\title{
Evidence-based antioxidant activity of the essential oil from Fructus $A$. zerumbet on cultured human umbilical vein endothelial cells' injury induced by ox-LDL
}

\author{
Xiang-chun Shen ${ }^{1 *}$, Ling Tao ${ }^{2}$, Wan-kui Li', Yan-yan Zhang ${ }^{1}$, Hong Luo ${ }^{1}$ and Yu-yi Xia ${ }^{1}$
}

\begin{abstract}
Background: The essential oil from Fructus Alpiniae zerumbet (FAZ) is its principal bioactive ingredient, and is widely used in Miao folk herbs in Guizhou province for the treatment of gastrointestinal and cardiovascular diseases. Several studies have confirmed that FAZ ameliorates hyperlipidemia and atherosclerosis. Because endothelial dysfunction often accompanies cardiovascular diseases, especially hyperlipidemia and atherosclerosis, the present study concentrated on evaluating the endothelial protective effects of the essential oil from FAZ (EOFAZ) on oxidized low-density lipoprotein (ox-LDL)-induced injury of cultured human umbilical vein endothelial cells (HUVECS) and on the regulation of oxidative stress.
\end{abstract}

Methods: Cell viability was analyzed with the MTT assay and trypan blue exclusion staining (TBES). Cell injury was assessed by lactate dehydrogenase $(\mathrm{LDH})$ release. Biochemical enzymatic methods were used to evaluate the oxidative stress, including the lipid peroxidation product, malondialdehyde (MDA), reduced glutathione (GSH), superoxide dismutase (SOD), catalase (CAT) and glutathione peroxidase (GSH-Px).

Results: The redox status of HUVECS was significantly exacerbated after exposure to ox-LDL. EOFAZ protected HUVECS against ox-LDL injury as assessed by the MTT assay, TBES and LDH release. Furthermore, EOFAZ ameliorated the oxidative stress by elevating the activities of SOD, CAT and GSH-Px, and increasing the GSH levels, in addition to attenuating the MDA contents.

Conclusions: The present data provide the first experimental evidence that EOFAZ protects endothelial cells against ox-LDL-induced injury, and indicate that this protection involves ameliorating the redox status.

Keywords: Essential oil, Fructus Alpiniae zerumbet, Human umbilical vein endothelial cells, Oxidized low-density lipoprotein, Oxidative stress

\section{Background}

It is well known that atherosclerosis (AS) is the leading cause of death in most Western countries, and is a crucial pathological factor in the development of cardiovascular diseases, leading to alterations and lesions in the inner walls of blood vessels [1]. Endothelial cells are crucial for maintaining the physiological functions of the cardiovascular system, and endothelial dysfunction has

\footnotetext{
* Correspondence: shenxiangchun@126.com

${ }^{1}$ Research Division of Pharmacology, Guiyang Medical University, Guiyang 55004, People's Republic of China

Full list of author information is available at the end of the article
}

been implicated in the initiation and propagation of AS processes [2]. Increasing evidence suggests that stress by an imbalanced cellular activity of production and elimination of reactive oxygen species (ROS) is involved in the pathophysiology of AS [3]. Although its etiology is multifactorial, endothelial dysfunctions, especially those elicited by oxidized low-density lipoproteins (ox-LDL), play a critical role in the pathogenesis of AS. ox-LDL promotes vascular dysfunction by exerting cytotoxicity directly on endothelial cells and by enhancing the production of inflammatory mediators, including ROS, proinflammatory cytokines and arachidonic acid metabolites [4]. 
Ameliorating the oxidative stress state can be a key therapeutic strategy against AS.

The Zingiberaceae is a large diverse family comprising 1,200 species belonging to 49 genera. A prominent member of this family is the Alpinia genus. Plants of this genus are used in herbal medicine all over the world. Alpinia zerumbet, also known as Alpinia speciosa or Alpinia nutans [5], is an aromatic perennial ginger herb originating in the East Indies and naturalized in the subtropical and tropical regions of South America, Oceania and Asia [6]. In phytotherapy, A. zerumbet has been shown to possess pharmacological activities, including as an antioxidant and in the treatment of various conditions such as intestinal disorders, hypertension and inflammation $[7,8]$.

In China, A. zerumbet is named Yanshanjiang, and has been used as a very valuable herbal medicine for hundreds of years. The herbalists used to separate each part of the A. zerumbet plant and apply them separately to different therapeutic uses. In particular as local Miao folk herbs in Guizhou province, the fruit was widely used against cardiovascular diseases. The essential oil from Fructus A. zerumbet (EOFAZ) has been shown to have major medicinal effects involving anti-inflammation, protection against cardiovascular diseases and antihypertension, as well as antioxidant activity $[9,10]$. Also, our previous research confirmed that the EOFAZ vasorelaxant effects depend on the endothelium-intact [11]. In another study we showed that compared to that of the fruit, the composition of the essential oil from the leaves is significantly different [12]. It is well known that oxLDL-induced endothelial cell injury is a key pathological process in atherosclerosis. Considering all these aspects, especially the EOFAZ endothelium ameliorating function and the antiatherosclerosis effect, the present study was undertaken to evaluate the amelioration of the cellular redox status by EOFAZ for prevention of ox-LDLinduced endothelial cell injury.

\section{Methods}

\section{Chemical and herbal materials}

The essential oil was extracted from the fruit of $A$. zerumbet, which was collected in Zhenfeng county, Guizhou province, China, in October 2009. The fruit was identified by Professor Chen $\mathrm{Zu}$-yun, and a voucher specimen (No.20091026) was deposited at the Research Division of Pharmacology, Guiyang Medical University. The isolation of the essential oil was carried out at the school of Pharmacy of the Guiyang Medical University, according to a method described elsewhere [13]. Briefly, chopped fruit was placed in a glass flask connected at one end to a glass vessel with water and at the other end to a water-cooled condenser. The water was heated to boiling point, and the steam percolated through the chopped fruit and collected in the condenser. After condensation, the watery phase with its solutes, termed the 'hydrolate', was separated from the oily phase; the essential oil when re-diluted in water is termed the 'pseudohydrolate'. Sixty-two compounds were separated and 58 were identified from the essential oil. The composition of EOFAZ was determined by gas chromatography and mass spectrometry: $\beta$-phellandrene (16.388\%), $\beta$-pinene (15.056\%), 1,8-cineole (10.956\%), camphene (10.120\%), $\alpha$-pinene (9.275\%), linalool L (4.026\%), camphor (3.657\%), O-cymene (3.384\%), $\beta$-myrcene (3.189\%), borneol L (2.446\%), caryophyllene oxide (1.778\%) and terpinen-4-ol (1.756\%); over 12 volatile compounds accounted for $82.03 \%$ of the total [12]. Pravastatin sodium standard substance (PRA) was purchased from the National Institute for the Control of Pharmaceutical and Biological Products of China, Beijing.

\section{Cell culture and treatments}

Cell cultures were carried out essentially as described previously $[14,15]$, with some modifications. Endothelial cells were isolated and pooled from human umbilical cords obtained less than $3 \mathrm{~h}$ after delivery (cords were obtained from three healthy puerperae donors, who gave informed consent, and the acquisition of tissues was carried out in line with the principles of the Declaration of Helsinki and all procedures with patients were approved by the ethical review board of Guiyang Medical University according to local and national guidelines). After rinsing, the veins were cannulated and incubated with $50 \mathrm{U} / \mathrm{ml}$ collagenase (Sigma-Aldrich, St. Louis, MO, USA) in serum-free M199 medium for $10 \mathrm{~min}$. Primary cultures were seeded at a concentration of approximately $4 \times 10^{4}$ cells $/ \mathrm{cm}^{2}$ onto $75-\mathrm{cm}^{2}$ flasks precoated with $0.01 \%(\mathrm{w} / \mathrm{v})$ polygeline in phosphate-buffered saline (PBS). The culture medium was used M199 with Earle's salts (Sigma-Aldrich), containing 20\% (v/v) human serum (Shanghai Hengyuan, Shanghai, China), $5 \mathrm{U} / \mathrm{ml}$ penicillin G, $5 \mathrm{pg} / \mathrm{ml}$ streptomycin sulfate and $150 \mathrm{pg} / \mathrm{ml}$ endothelial cell growth supplement (Sigma-Aldrich). Cells reached confluency within approximately $4 \mathrm{~d}$, and were cultured at $37^{\circ} \mathrm{C}$ in a humidified atmosphere with $5 \% \mathrm{CO}_{2}$. The medium was changed a day after seeding and every $2 \mathrm{~d}$ thereafter.

For all experiments, cells were used at passages 3 to 6 and seeded at a concentration of $1 \times 10^{5}$ cells $/ \mathrm{ml}$ in 96well plates, 24-well plates, or six-well plates. Treatments were carried out on a confluent monolayer of cells. EOFAZ was freshly prepared as a stock solution in DMSO and diluted with culture medium. DMSO was present at an equal concentration $(0.02 \%$ final concentration) in all groups except for the PRA group. ox-LDL was used for no more than 2 wk from the date of production (Yiyuan Biotechnology, Guangzhou, China). 
Cells were preincubated for 30 min with EOFAZ or PRA before being exposed to $100 \mathrm{mg} / \mathrm{L}$ ox-LDL for $24 \mathrm{~h}$ except for the control group. After treatment, the cells cultured in the 96-well plates were used for the 3-(4,5dimethylthiazol-2-yl)-2,5-diphenyltetrazolium bromide (MTT; Sigma-Aldrich) assay, those in the six-well plates were used for trypan blue (Beyotime, Haimen, China) exclusion staining (TBES), and those in the 24well plates were assayed for the contents of malondialdehyde (MDA), glutathione (GSH) and LDH, and for the anti-oxidative enzymatic activity of superoxide dismutase (SOD), catalase (CAT) and glutathione peroxidase (GSH-Px). All experiments were performed in triplicate (four or five cultures were used for the experiments), however, the TBES assay was performed only once, but on four cultures.

\section{Cell viability measurements by the MTT assay and TBES}

Cell viability was measured by the MTT reduction assay as previously described [16]. Cells from at least six wells were used for each group. Briefly, after a $24 \mathrm{~h}$ exposure to ox-LDL $(100 \mathrm{mg} / \mathrm{L})$, the supernatant was removed and the cells were gently washed with PBS followed by $80 \mu \mathrm{l}$ of fresh culture medium and addition of $20 \mu \mathrm{l}$ MTT $(5 \mathrm{mg} / \mathrm{ml})$. After $4 \mathrm{~h}$ of incubation, $200 \mu \mathrm{l}$ of DMSO, the solubilization/stop solution, was added to dissolve the formazan crystals, and the absorbance was read by a microplate reader (Sunrise RC, Tecan, Switzerland) at a wavelength of $570 \mathrm{~nm}$. Inhibition of cell damage (\%) was calculated with the following formula:

Inhibition of cell damage (\%)

$$
\begin{aligned}
& =\left(\mathrm{OD}_{\text {treated group }}-\mathrm{OD}_{\mathrm{ox}-\mathrm{LDL} \text { group }}\right) \\
& \quad /\left(\mathrm{OD}_{\text {control group }}-\mathrm{OD}_{\mathrm{ox}-\mathrm{LDL} \text { group }}\right) \\
& \quad \times 100
\end{aligned}
$$

The TBES method is another classic cell viability method [17]. HUVECs in six-well plates were pretreated with EOFAZ or PRA for $30 \mathrm{~min}$ and then stimulated with $100 \mathrm{mg} / \mathrm{L}$ ox-LDL for $24 \mathrm{~h}$. Then the cells were harvested and centrifuged to remove the medium. Cells were washed three times with PBS and resuspended to make a suspension of $1 \times 10^{6}$ cells $/ \mathrm{ml}$. The suspension was mixed with $0.4 \%$ trypan blue dye for $5 \mathrm{~min}$ at $25^{\circ} \mathrm{C}$, and the unstained (viable) and stained (nonviable) cells were counted on a hemacytometer within $5 \mathrm{~min}$ in five $40 \times$ microscope fields per well.

\section{LDH activity in the medium}

To evaluate cell injury, the LDH released from the cytosol into the culture medium was measured as previously described [18]. After treatment with EOFAZ or PRA, followed by incubation with $100 \mathrm{mg} / \mathrm{L}$ ox-LDL for $24 \mathrm{~h}$, the medium was collected from each well. Supernatants were obtained by centrifugation at $12,000 \times \mathrm{g}$ at $4^{\circ} \mathrm{C}$ for $10 \mathrm{~min}$. $\mathrm{LDH}$ release was determined using an $\mathrm{LDH}$ assay kit according to the manufacturer's instructions (Nanjing Jiancheng Co., Nan Jing, China). In brief, 100 $\mu \mathrm{l}$ supernatant, $250 \mu \mathrm{l}$ buffer and $50 \mu \mathrm{l}$ coenzyme were mixed and incubated for $15 \mathrm{~min}$ at $37^{\circ} \mathrm{C}$, followed by addition of $250 \mu \mathrm{l}$ 2,4-dinitrophenylhydrazine and another $15 \mathrm{~min}$ incubation at $37^{\circ} \mathrm{C}$ in the dark. Finally, 2.5 $\mathrm{ml} \mathrm{NaOH}(0.4 \mathrm{~mol} / \mathrm{L})$ were added to the reaction mixture. Three minutes later, $200 \mu \mathrm{l}$ of each reaction mixture were transferred into a new 96-well plate. The absorbance was read at $440 \mathrm{~nm}$ with an ELISA reader.

\section{Cell lysate preparation}

HUVECs were pretreated with EOFAZ or PRA for 30 min and then incubated with $100 \mathrm{mg} / \mathrm{L}$ ox-LDL for $24 \mathrm{~h}$ in 24-well plates. The cells were lysed with extraction buffer (20 mM Tris- $\mathrm{HCl}, \mathrm{pH}$ 7.5, $150 \mathrm{mM} \mathrm{NaCl}, 1 \mathrm{mM}$ EDTA, 1 mM EGTA, 1\% Triton X-100, 2.5 mM sodium pyrophosphate, $1 \mathrm{mM}$ glycerophosphate, $1 \mathrm{mM} \mathrm{Na}_{3} \mathrm{VO}_{4}$, $1 \mu \mathrm{g} / \mathrm{ml}$ leupeptin and $1 \mathrm{mM}$ PMSF). Cell lysates from each well were collected and used for determination of MDA and GSH contents and anti-oxidative enzymatic activity. Protein concentrations of cell extracts were determined by the BCA assay (Santa Cruz Biotechnologies, Santa Cruz, CA, USA).

\section{Measurement of malondialdehyde (MDA) and glutathione (GSH) concentrations}

The total levels of MDA, the lipid peroxidation product in the lysates, were measured by the thiobarbituric acidreactive substance (TBARS) assay as described previously [19]. The lysates $(100 \mu \mathrm{l})$ were mixed in glass test tubes with $3 \mathrm{ml}$ of $1 \%$ phosphoric acid, $1 \mathrm{ml}$ of $0.67 \%$ thiobarbituric acid and $0.04 \%$ butylated hydroxytoluene, and the mixtures were incubated in a boiling water bath for $60 \mathrm{~min}$. Marbles were placed on the tops of the tubes during the incubation period to avoid excessive loss of reaction mixture. After cooling the tubes in ice, $1.5 \mathrm{ml}$ of $n$-butanol were added and the reaction mixture was centrifuged at $1000 \times \mathrm{g}$ for $10 \mathrm{~min}$. The absorbance of the supernatant was read at $535 \mathrm{~nm}$. The concentrations of TBARS were calculated using tetraethoxypropane as a reference standard. Results were expressed in $\mathrm{nmol} / \mathrm{mg}$ protein.

Intracellular GSH was measured using the enzymatic recycling assay [20]. Aliquots $(20 \mu \mathrm{l})$ were mixed with $100 \mathrm{mM}$ TEA, $600 \mathrm{mM}$ DTNB, and $210 \mathrm{mM} \mathrm{NADPH}$ in $6.3 \mathrm{mM}$ EDTA-0.125 mM NaH $\mathrm{PO}_{4}, \mathrm{pH} 7.5$ buffer. The final volume was $200 \mu \mathrm{l}$ and the reaction was initiated by adding 0.1 units GSH reductase. Absorbance was read at $405 \mathrm{~nm}$ in a 96-well plate format using an ELX800 microplate reader (Bio Tek, Winooski, VT, USA), and concentrations were determined using purified GSH 
as standard and expressed as nmoles of GSH per mg of protein (nmol/mg protein).

\section{Activity assay of anti-oxidative enzymes}

SOD activity was measured by the xanthine/xanthine oxidase mediated ferricytochrome c reduction assay [21]. One unit of SOD activity was defined as the amount that reduced the absorbance at $550 \mathrm{~nm}$ by $50 \%$. Fifty microliters of lysates were added to $2.9 \mathrm{ml}$ of reaction buffer $(0.5 \mu \mathrm{mol}$ xanthine, $0.1 \mathrm{mM} \mathrm{NaOH}$ and $2 \mu \mathrm{mol}$ cytochrome c in $50 \mathrm{mM} \mathrm{K} \mathrm{HPO}_{4}-\mathrm{Na}_{2} \mathrm{HPO}_{4} / 0.1 \mathrm{mM}$ EDTA, $\mathrm{pH}$ 7.8). The reaction was initiated by adding $50 \mu \mathrm{l}$ of xanthine oxidase solution $(0.2 \mathrm{U} / \mathrm{ml}$ in $0.1 \mathrm{mM}$ EDTA). The absorbance change was monitored for $3 \mathrm{~min}$ at $25^{\circ} \mathrm{C}$. Activities were calculated using a concurrently run standard curve and expressed per mg of protein. The SOD activity results were expressed as $\mathrm{U} / \mathrm{mg}$ protein.

The GSH-Px activity assay was conducted by quantifying the rate of oxidation of the reduced glutathione (GSH) to the oxidized glutathione by $\mathrm{H}_{2} \mathrm{O}_{2}$, which is catalyzed by GSH-Px. One unit of GSH-Px was defined as the amount that reduced the level of GSH by $1 \mu \mathrm{mol} / \mathrm{L}$ in $1 \mathrm{~min}$ per mg protein. GSH-Px activity was measured in a $1.0 \mathrm{ml}$ cuvette containing $400 \mu \mathrm{l}$ of $0.25 \mathrm{M}$ potassium phosphate buffer ( $\mathrm{pH}$ 7.0), $200 \mu \mathrm{l}$ of sample, $100 \mu \mathrm{l}$ of $10 \mathrm{mM} \mathrm{GSH}, 100 \mu \mathrm{l}$ of $2.5 \mathrm{mM}$ NADPH and $100 \mu \mathrm{l}$ of glutathione reductase $(6 \mathrm{U} / \mathrm{ml})$. Hydrogen peroxide $(100 \mu \mathrm{l}$ of $12 \mathrm{mM})$ was then added, and the change in absorbance was measured at $1 \mathrm{~min}$ intervals for $5 \mathrm{~min}$ at $366 \mathrm{~nm}$ [22]. GSH-Px activity was expressed as U/mg protein compared to the standard.

CAT activity was detected by methods of our lab [23]. Briefly, $2.8 \mathrm{ml}$ of $10 \mathrm{mmol} / \mathrm{L} \mathrm{H}_{2} \mathrm{O}_{2}$ were added to a $5 \mathrm{ml}$ cuvette that contained $0.2 \mathrm{ml}$ of $1 \mathrm{~mol} / \mathrm{L}$ Tris- $\mathrm{HCl}(\mathrm{pH}$ 8.0) in an ice-water bath, and absorbance was measured immediately at $240 \mathrm{~nm}$, which was $\mathrm{OD}_{0}$. Then $10 \mu \mathrm{l}$ of lysate were added to the cuvette. The mixture was incubated at $25^{\circ} \mathrm{C}$ for $4 \mathrm{~min}$, and then absorbance was measured, which was $\mathrm{OD}_{4}$. For the nonenzymatic reaction cuvette, the procedure was the same as for the enzymatic cuvette, but the cell lysate supernatant was substituted by distilled water, which was $\mathrm{OD}_{\mathrm{n}}$. The results were expressed as catalytic activity following the equation: $\mathrm{U} / \mathrm{mg}$ protein $=\left(\mathrm{OD}_{0}-\mathrm{OD}_{4}-\mathrm{OD}_{\mathrm{n}}\right) \times \mathrm{CH}_{2} \mathrm{O}_{2} /$ $\mathrm{C}_{\text {protein }} \times 4$.

\section{Statistical analysis}

Data were expressed as mean \pm S.E.M (standard error of the mean) of at least three independent experiments. The differences in mean values among the experimental groups were measured using two-tailed analysis of variance (ANOVA) followed by Dunnett's test. Differences were considered statistically significant at $p<0.05$.

\section{Results}

EOFAZ attenuates the MTT reduction and blue staining ratio of HUVECs induced by ox-LDL

The MTT assay utilizes the yellow MTT, which is metabolized by the mitochondrial succinate dehydrogenase to yield a purple formazan reaction product. Exposure of endothelial cells to $100 \mathrm{mg} / \mathrm{L}$ ox-LDL for $24 \mathrm{~h}$ significantly reduced cell viability (Table $1 ; 1.85 \pm 0.11$ in control vs. $0.98 \pm 0.12$ in $100 \mathrm{mg} / \mathrm{L}$ ox-LDL alone, $p<0.01)$. Preincubation with $0.1 \mathrm{mg} / \mathrm{L}$ EOFAZ restored viability significantly, but 0.01 $\mathrm{mg} / \mathrm{L}$ EOFAZ had no effect $(1.25 \pm 0.20$ and $1.09 \pm 0.25$ vs. $0.98 \pm 0.12$, respectively, $p<0.01$ and $p>0.05$; Table 1$)$. A similar protective effect was observed in the PRA treated group. The potential toxicity of EOFAZ to HUVECs was examined by addition of EOFAZ at $0.01,0.1,1$ and $10 \mathrm{mg} / \mathrm{L}$ to the vehicle control medium. These concentrations had no effect on the survival of HUVECs, except for the $10 \mathrm{mg} / \mathrm{L}$ that led to a significant reduction in viability data were not shown. These results suggest that EOFAZ at concentrations of up to $1 \mathrm{mg} / \mathrm{L}$ is effective and safe to use with HUVECs. The trypan blue staining exclusion test is widely used to determine the number of viable cells present in a cell suspension. After incubation with $100 \mathrm{mg} / \mathrm{L}$ ox-LDL for $24 \mathrm{~h}$, the number of stained cells significantly increased compared with the control group, and EOFAZ-pretreatment significantly decreased the cell blue staining ratio (Figure 1).

\section{EOFAZ inhibits LDH release from cells treated} with ox-LDL

A $24 \mathrm{~h}$ exposure to $100 \mathrm{mg} / \mathrm{L}$ ox-LDL resulted in a marked and significant facilitation of LDH release from the cells, compared with the vehicle control group (555.15 $\pm 59.67 \mathrm{U} / \mathrm{L}$ vs. $269.12 \pm 97.80 \mathrm{U} / \mathrm{L}, p<0.01)$. In contrast, the LDH activity in the supernatant was significantly decreased in the samples pretreated with $0.1 \mathrm{mg} / \mathrm{L}$ EOFAZ compared with the samples treated with ox-LDL alone $(328.68 \pm 61.29 \mathrm{U} / \mathrm{L}$ vs. $555.15 \pm 59.67 \mathrm{U} / \mathrm{L}, p<0.01$; Figure 2).

$\begin{aligned} & \text { Table } 1 \text { Protective effects of EOFAZ on HUVECs' injury } \\
& \text { induced by ox-LDL }\end{aligned}$
\begin{tabular}{llll}
\hline Groups & Dose $(\mathbf{m g} / \mathrm{L})$ & $\mathrm{OD}_{570}$ & $\begin{array}{l}\text { Inhibition of cell } \\
\text { damage (\%) }\end{array}$ \\
\hline Control & - & $1.85 \pm 0.11$ & \\
Ox-LDL & 100 & $0.98 \pm 0.12^{\# \#}$ & \\
ox-LDL+EOFAZ & $100+0.1$ & $1.25 \pm 0.20^{* *}$ & 31.0 \\
& $100+0.01$ & $1.09 \pm 0.25$ & 12.6 \\
Ox-LDL+PRA & $100+10 \mu \mathrm{mol} / \mathrm{L}$ & $1.19 \pm 0.21^{*}$ & 24.1 \\
\hline
\end{tabular}

$\# \# p<0.01$, compared with the control group; ${ }^{*} p<0.05$ and ${ }^{* *} p<0.01$, compared with the ox-LDL group. 


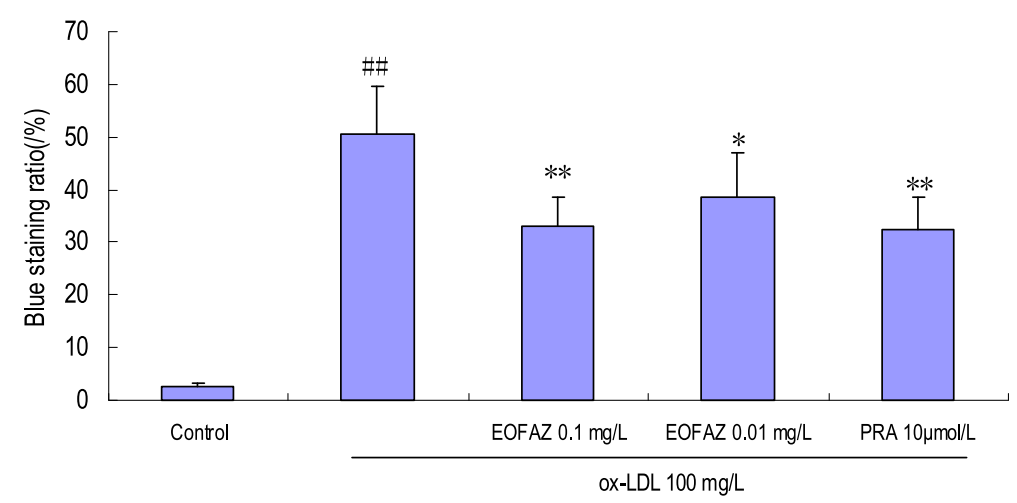

Figure 1 Effects of EOFAZ on trypan blue exclusion staining in HUVECs' injury induced by ox-LDL. HUVECs were pretreated for 30 min with EOFAZ or PRA, and then exposed to $100 \mathrm{mg} / \mathrm{L}$ ox-LDL for $24 \mathrm{~h}$. A cell suspension was mixed with a $0.4 \%$ trypan blue dye for $5 \mathrm{~min}$ at $25^{\circ} \mathrm{C}$, and the unstained (viable) and stained (nonviable) cells were counted in a hemacytometer. The values shown are mean \pm S.E.M. of three experiments (four or five cultures per experiment). ${ }^{\# \#} p<0.01$, vs. control group; ${ }^{*} p<0.05$, ${ }^{* *} p<0.01$, vs. ox-LDL group.

\section{EOFAZ reduces the MDA contents and increases the GSH} contents in cells treated with ox-LDL

In the present study, incubation of HUVECs with 100 $\mathrm{mg} / \mathrm{L}$ ox-LDL for $24 \mathrm{~h}$ resulted in a significant increase in the MDA contents, which was significantly attenuated by EOFAZ or PRA pretreatment (Figure 3). However, the exposure of HUVECs to ox-LDL $100 \mathrm{mg} / \mathrm{L}$ for $24 \mathrm{~h}$ resulted in a significant decrease in GSH contents, which was ameliorated by preincubation with EOFAZ or PRA (Figure 4).

\section{EOFAZ upregulates the activities of antioxidant enzymes}

The main scavengers responsible for inactivation and termination of free oxygen radicals are SOD, CAT, and the glutathione system. Our results indicated that the activities of the anti-oxidative enzymes were significantly decreased after HUVECs were exposed to $100 \mathrm{mg} / \mathrm{L}$ oxLDL, and that EOFAZ and PRA improved these activities (Figures 5, 6 and 7). Preincubation with $0.1 \mathrm{mg} / \mathrm{L}$
EOFAZ significantly ameliorated the activities of SOD, CAT and GSH-Px in the cell lysates. Preincubation with $0.01 \mathrm{mg} / \mathrm{L}$ EOFAZ enhanced the activities of these enzymes, however, these results were not statistically significant. PRA $(10 \mu \mathrm{mol} / \mathrm{L})$ alleviated the decreased activities of SOD and CAT $\left({ }^{* * *} p<0.01\right.$, compared with the ox-LDL treatment), but did not improve the GSH-Px activity.

\section{Discussion}

To the best of our knowledge, the present study demonstrates for the first time that EOFAZ (the composition was significantly different from previous reports and from the essential oil extract from the fruit of A. zerumbet) protects against endothelial cell injury induced by ox-LDL via ameliorating oxidative stress, which may be the main underlying mechanism.

Human umbilical vein endothelial cells (HUVECs) have played a major role as a model system for studying

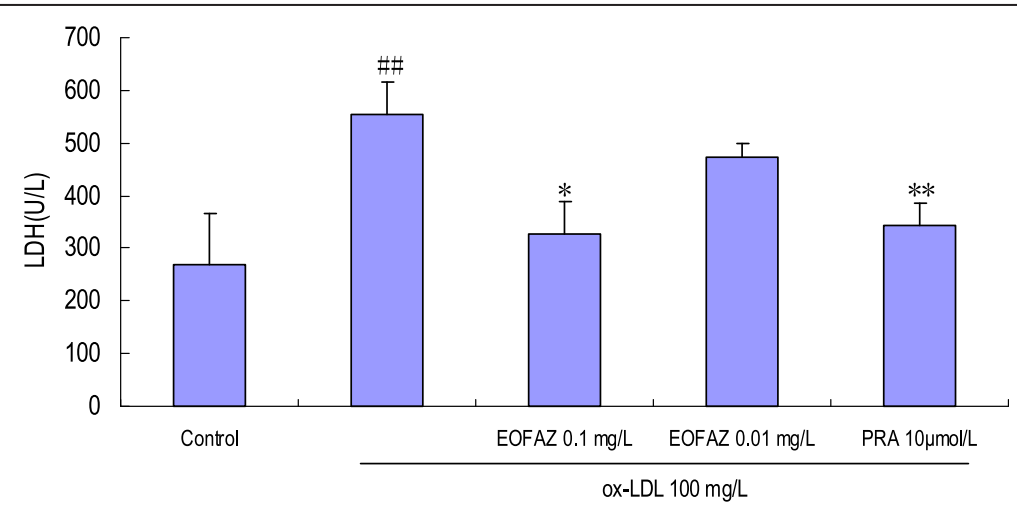

Figure 2 Effects of EOFAZ on LDH activity in HUVECs' injury induced by ox-LDL. HUVECs were treated as described in Figure 1, and then the culture medium was collected to examine LDH activity. The values shown are mean \pm S.E.M. of three experiments (four or five cultures per experiment). ${ }^{\# \#} p<0.01$, vs. control group; ${ }^{*} p<0.05$, ${ }^{* *} p<0.01$, vs. ox-LDL group. 


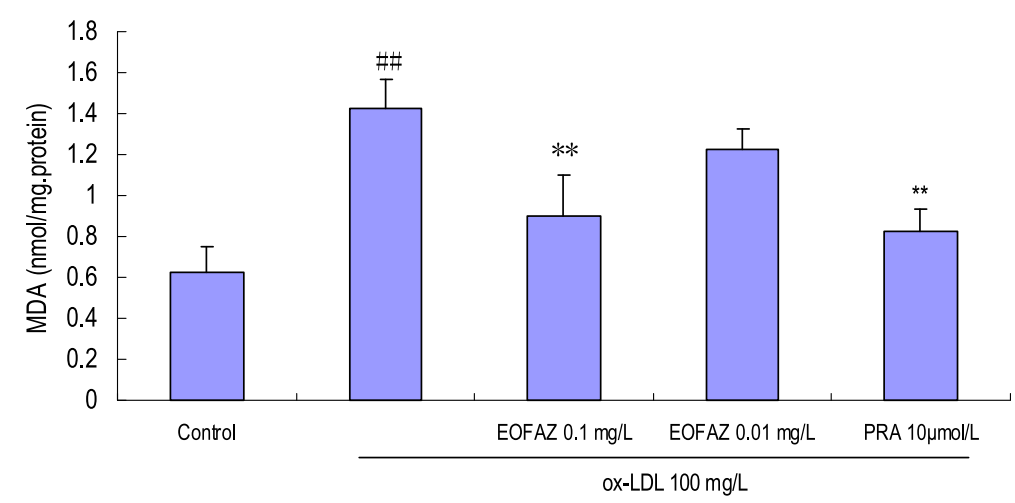

Figure 3 Effects of EOFAZ on MDA contents in HUVECs' injury induced by ox-LDL. HUVECs were treated as described in Figure 1, followed by cell lysate preparation. MDA contents was measured with the thiobarbituric acid-reactive substance (TBARS) assay. The values shown are mean \pm S.E.M. of three experiments (four or five cultures per experiment). ${ }^{\# \#} p<0.01$, vs. control group; ${ }^{* *} p<0.01$, vs. ox-LDL group.

the regulation of endothelial cell function and the role of the endothelium in the response of the blood vessel wall to stretch, shear forces, and the development of atherosclerotic plaques and angiogenesis [24]. It is well known that the atherosclerotic lesion is characterized by an accumulation of lipids carried by lipoproteins, such as low-density lipoprotein (LDL). LDL becomes susceptible to (non)enzymatic oxidative modifications when retained in the artery wall [25]. These modifications make LDL a potent effector of cellular functions. Multiple lines of evidence suggest that oxidative stress, characterized by an elevated generation of ROS, is involved in the pathogenesis of AS, which implies that oxidized-LDL may promote the development of AS through oxidative stress, and is one of the most important risk factors for AS and cardiovascular morbidity [26]. Endothelial dysfunction elicited by ox-LDL has been demonstrated as the key step in the initiation of AS. It is widely accepted that ox-LDL-induced endothelial dysfunction is associated with an alteration of the cell redox status, and ameliorating the redox status has been a key therapeutic strategy against AS in the clinic [27].

The cell injury was evaluated by the MTT assay, TBES, and LDH release, which are widely accepted methods for cell injury evaluation. The MTT assay is a quantitative colorimetric method to determine cell proliferation or injury. It utilizes the yellow MTT, which is metabolized by the mitochondrial succinate dehydrogenase to yield a purple formazan reaction product. The TBES method is widely used to determine the number of viable cells and is based on the principle that live cells possess intact cell membranes that exclude certain dyes, such as trypan blue, eosin and propidium, whereas dead cells do not. Lactate dehydrogenase (LDH) is a stable enzyme in the cytosol, present in all cell types, that is rapidly released into the medium upon damage of the plasma membrane; hence it is a biomarker for cell membrane damage. The cell injury induced by incubation with ox-LDL for $24 \mathrm{~h}$ was confirmed by the MTT assay $\left(\mathrm{OD}_{570}\right.$ decrease), trypan blue staining ratio increase,

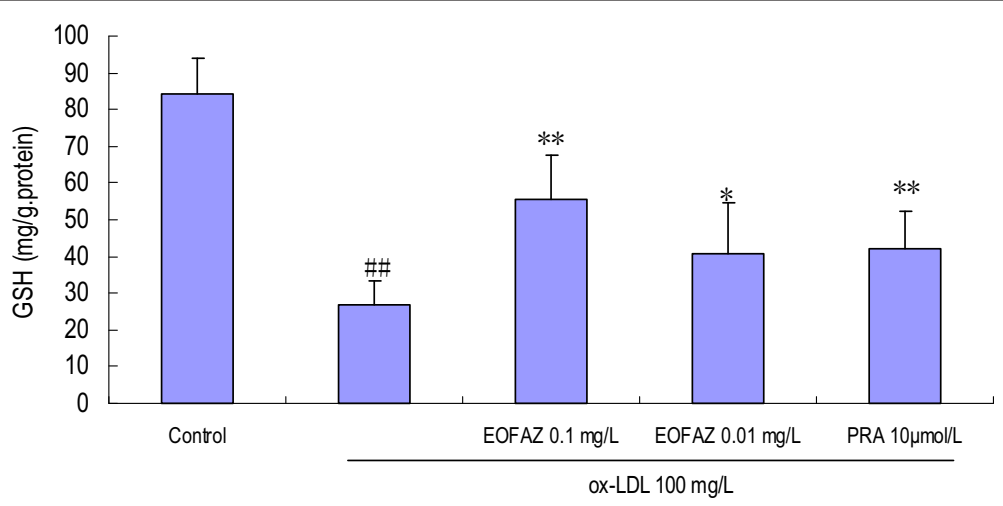

Figure 4 Effects of EOFAZ on GSH contents in HUVECs' injury induced by ox-LDL. HUVECs treatment and cell lysate preparation were performed as described in Figure 3. The enzymatic recycling assay was used to detect the GSH contents. The values shown are mean \pm S.E.M. of three experiments (four or five cultures per experiment). ${ }^{\# \#} p<0.01$, vs. control group; ${ }^{*} p<0.05$, ${ }^{* *} p<0.01$, vs. ox-LDL group. 


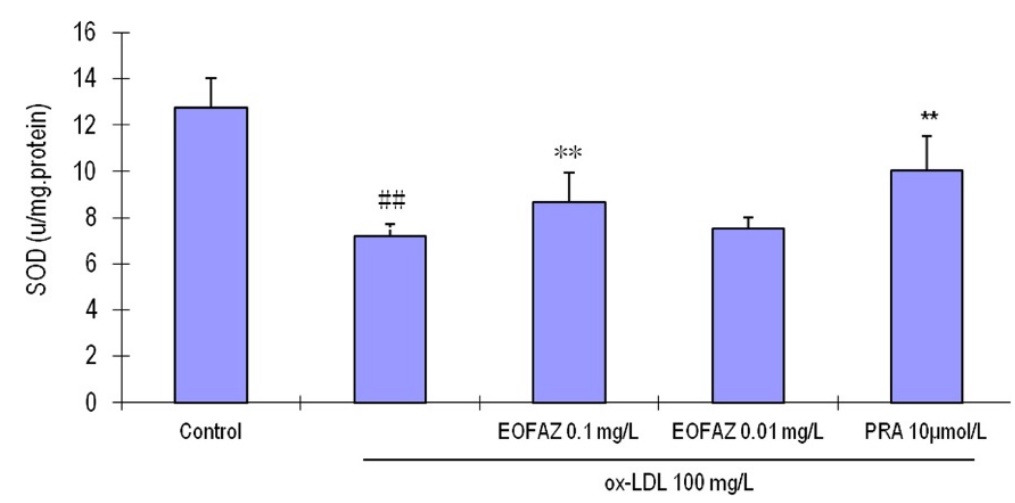

Figure 5 Effects of EOFAZ on SOD activity in HUVECs exposed to ox-LDL. HUVECs treatment and cell lysate preparation were performed as described in Figure 3. SOD activity was measured by the xanthine/xanthime oxidase mediated ferricytochrome $\mathrm{c}$ reduction assay. The values shown are mean \pm S.E.M. of three experiments (four or five cultures per experiment). ${ }^{\# \#} p<0.01$, vs. control group; ${ }^{* *} p<0.01$, vs. ox-LDL group.

and the LDH activity increase. Pretreatment with EOFAZ or PRA ameliorated the cell injury.

Membranes of bioplasm are very rich in polyunsaturated fatty acids, which are especially sensitive to free radical-induced lipid peroxidation. In oxidative stress, superoxide anion and hydrogen peroxide are formed and cannot be readily scavenged because of the low activities of CAT, SOD and GSH-Px in the endothelial cell [28]. Augmentation of endogenous antioxidants (SOD, CAT and (GSH-Px) has been recognized as an important pharmacological property present in natural as well as many synthetic compounds [29]. This constitutes a major mechanism of protection against oxidative stress $[30,31]$. The most abundant ROS generated in living systems is the superoxide radical, which is acted upon by SOD to produce hydrogen peroxide, which in turn is broken down by catalase and/or GSH-Px into water and oxygen. Thus, increase in both SOD and catalase along with GSH-Px activity is considered to be more beneficial in the event of oxidative stress.
Exposure to $100 \mathrm{mg} / \mathrm{L}$ ox-LDL for $24 \mathrm{~h}$, increased the MDA contents, decreased the GSH contents, and inhibited the enzymes' antioxidant activity, indicating that the redox status was exacerbated. In the present study, a 30 min preincubation with EOFAZ significantly elevated the activities of SOD, CAT and GSH-Px, whereas PRA only enhanced the activity of SOD and CAT. Obviously, EOFAZ scavenged hydrogen peroxide and superoxide anion, further decreasing the formation of hydroxyl radicals and attenuating lipid peroxidative damage after the HUVECs were exposed to ox-LDL. However, it is not clear whether EOFAZ induces the expression of the endogenous antioxidant enzymes or whether it has direct protective effects of endogenous antioxidants. PRA, a hydroxymethylglutaryl-CoA reductase inhibitor, is a member of the statins drug class and was used here as a positive control. PRA, which is used for lowering cholesterol and preventing cardiovascular disease, and is widely used to prevent AS, has anti-oxidative effects [32]. The present results confirmed previous research.

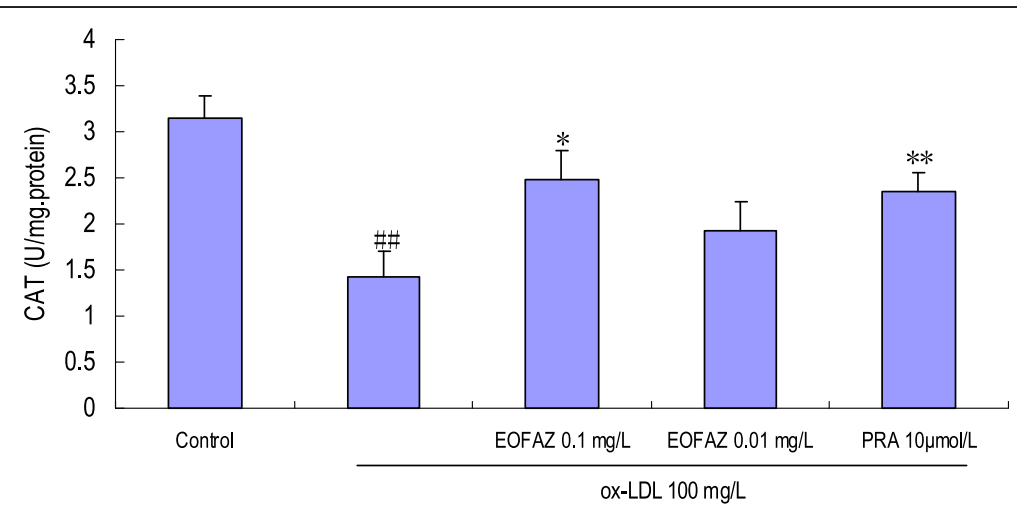

Figure 6 Effects of EOFAZ on CAT activity in HUVECs exposed to ox-LDL. HUVECs treatment and cell lysate preparation were performed as described in Figure 3. CAT activity was assayed as described in the Methods section. The values shown are mean \pm S.E.M. of three experiments (four or five cultures per experiment). ${ }^{\# \#} p<0.01$, vs. control group; ${ }^{* *} p<0.01$, vs. ox-LDL group. 


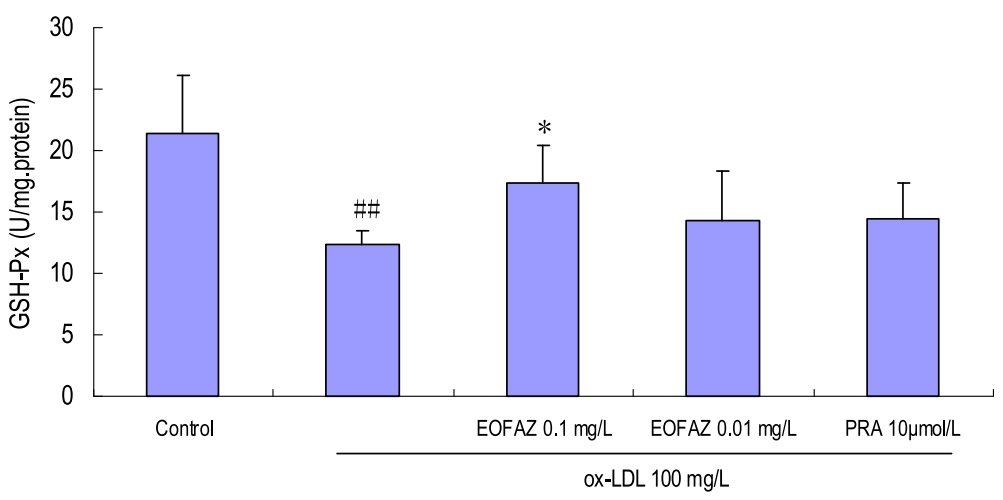

Figure 7 Effects of EOFAZ on GSH-Px activity in HUVECs exposed to ox-LDL. HUVECs treatment and cell lysate preparation were performed as described in Figure 3. GSH-Px activity was determined by quantifying the rate of oxidation of the reduced glutathione (GSH) to the oxidized glutathione (GSSG) by $\mathrm{H}_{2} \mathrm{O}_{2}$, which is catalyzed by GSH-Px. The values shown are mean \pm S.E.M. of three experiments (four or five cultures per experiment). ${ }^{\# \#} p<0.01$, vs. control group; ${ }^{*} p<0.05$, vs. ox-LDL group.

Oxidative metabolites are involved in the functional inactivation of endothelial cells by increasing permeability and as potent inducers of endothelial cell death. The level of MDA reflects the extent of cell damage by oxidative stress [33]. GSH is an intracellular reductant that plays major roles in catalysis, metabolism and transport, and protects cells against free radicals, peroxides, and other toxic compounds, as it is a critical factor involved in the glutathione system to scavenge hydrogen peroxide and organic hydroperoxides [34]. It is well known that a deficiency in GSH within living organisms can lead to tissue disorders and injury. The present study demonstrated that EOFAZ alleviated the increase in MDA and the decrease in GSH contents caused by the ox-LDLinduced endothelial cell damage, suggesting it has the potential to protect the membranes of HUVECs from lipid peroxidative damage.

Endothelial dysfunction is an early feature of both atherosclerosis and vascular diseases, which may lead to an improvement of prognosis in patients with cardiovascular risk factors preventing the development of atherosclerosis and consequently promoting a reduction in cardiovascular events [35]. Chronic inflammation and oxidative stress play crucial roles in endothelial dysfunction and atherosclerosis [36]. Controlling a variety of risk factors causing inflammation and oxidative stress with combination therapy may simultaneously address multiple mechanisms underlying the pathogenesis of atherosclerosis. EOFAZ has been shown to be an antiinflammatory agent in previous research [37] and the current results confirmed it is also an antioxidant, which may provide a novel therapy for atherosclerosis in the clinic.

In summary, the present research indicates that increase in HUVECs' lipid peroxidation and depletion of endogenous antioxidants support the occurrence of oxidative stress after exposure to ox-LDL. Furthermore, it was accompanied by cell viability decrease, which was confirmed by the MTT assay, trypan blue exclusion, and LDH release. EOFAZ protected the cells against oxidative stress, as evidenced by inhibition of the increased MDA contents and decreased GSH contents, alleviation of CAT, SOD and GSH-Px activities, and finally, enhancement of cell viability. The mechanism of this protection can be attributed to the augmented endogenous antioxidant reserve in HUVECs and/or a direct antioxidant effect. This study shows that EOFAZ from natural products may be an excellent protecting agent against endothelial cell injury in the clinic; the mechanism will be explored in detail and a clinical evaluation conducted in future research.

\section{Conclusions}

The present findings provide the first experimental evidence that EOFAZ protects endothelial cells against oxLDL-induced injury, and indicate that this protection involves amelioration of the redox status.

\section{Ethics approval}

This study was approved by the ethical review board of Guiyang Medical University according to local and national guidelines. Care of the patients in this study was in accordance with the Declaration of Helsinki and all relevant laws.

\section{Abbreviations}

AS: Atherosclerosis; CAT: Catalase; DMSO: Dimethyl sulfoxide; EOFAZ: Essential oil from Fructus Alpiniae Zerumbet; FAZ: Fructus Alpiniae Zerumbet; GSH: Reduced glutathione; GSH-Px: Glutathione peroxidase; HUVECS: Human umbilical vein endothelial cells; LDH: Lactate dehydrogenase; MDA: Malondialdehyde; MTT: 3-(4,5-dimethylthiazol-2-yl)2,5-diphenyltetrazolium bromide; OD: Optical density; ox-LDL: Oxidized lowdensity lipoprotein; PBS: Phosphate-buffered saline; ROS: Reactive oxygen species; PRA: Pravastatin; SOD: Superoxide dismutase; TBES: Trypan blue exclusion staining. 


\section{Competing interests}

The authors declare that they have no competing interests.

\section{Authors' contributions}

XS: Supervised the work, provided the grant, designed and performed the study, evaluated the data, prepared and corrected the manuscript, and coordinated the study. LT: Prepared the essential oil from Fructus Alpiniae Zerumbet and performed the biochemical assays. WL: Performed the study and analyzed the data. YZ, HL and YX: Performed the biochemical assays. All authors read and approved the final manuscript.

\section{Acknowledgments}

This research was supported by grants from the National Natural Science Foundation of China (No: 30960531), the Training Program of Guizhou Provincial Excellent Talented Scientists and Technicians (No: 2009-28), the Excellent Scientific and Technological and Educational Talents of Governor's Special Fund in Guizhou Province (No: G2011-2), the Science and Technology Research Key Project of the Ministry of Education (No: 211166), and the Modern Chinese Medicine of Guizhou Province (No:2012-5051).

\section{Author details}

${ }^{1}$ Research Division of Pharmacology, Guiyang Medical University, Guiyang 55004, People's Republic of China. 'Department of Pharmaceutics, Guiyang Medical University, Guiyang 55004, People's Republic of China.

Received: 12 May 2012 Accepted: 5 October 2012

Published: 7 October 2012

\section{References}

1. Stocker R, Keaney FJ: Role of oxidative modifications in atherosclerosis. Physiol Rev 2004, 84(4):1381-1478.

2. Fotis L, Agrogiannis G, Vlachos IS, Pantopoulou A, Margoni A, Kostaki M, Verikokos C, Tzivras D, Mikhailidis DP, Perrea D: Intercellular adhesion melecule ( ICAM )-1 and vascular cell adhesion molecule ( VCAM )-1 at the early stages of atherosclerosis in a rat model. In Vivo 2012, 26(2):243-250

3. Lum H, Roebuck KA: Oxidant stress and endothelial cell dysfunction. Am J Physiol Cell Physiol 2001, 280(4):C719-C741.

4. Mitra S, Deshmukh A, Sachdeva R, Lu J, Mehta JL: Oxidized low-density lipoprotein and atherosclerosis implications in antioxidant therapy. Am J Med Sci 2011, 342(2):135-142.

5. Mendonca VL, Oliveira CL, Craveiro AA, Rao VS, Fonteles MC: Pharmacological and toxicological evaluation of Alpinia specosa. Mem Inst Oswaldo Cruz 1991, 86(Suppl 2):93-97.

6. Murakami S, Li W, Matsuura M: Composition and seasonal variation of essential oil in Alpinia zerumbet from Okinawa Island. J Nat Med 2009, 63(2):204-208

7. Yob NJ, Jofrry SM, Affandi MM, The LK, Sallen MZ, Zakaria ZA: Zingiber zerumbet (L.) Smith: a review of its ethnomedicinal, chemical, and pharmacological uses. Evid Based Complement Alternat Med 2011, 2011:543216.

8. Chompoo J, Upadhyay A, Fukuta M, Tawata S: Effect of Alpinia zerumbet components on antioxidant and skin diseases-related enzymes. BMC Complement Altern Med 2012, 12(1):106

9. Chuang CM, Wang HE, Peng CC, Chen KC, Peng RY: Hypolipidemic effects of different angiocarp parts of Alpinia zerumbet. Pharm Biol 2011, 49(12):1257-1264.

10. Lin LY, Peng CC, Liang YJ, Yeh WT, Wang HE, Yu TH, Peng RY: Alpinia zerumbet potentially elevates high-density lipoprotein cholesterol level in hamsters. J Agric Food Chem 2008, 56(12):4435-4443.

11. Tao $L, X i a o ~ T T, H u H S$, Tu L, Liu XD: Effects of volatile oils from fructus Alpiniae zerumber on the contraction of rabbit thoracic aorta in vitro. Chin Hosp Pharm J 2010, 30(23):1966-1969.

12. Shen XC, Hu HS, Xiao HT: GC-MS analysis of chemical constituents of the essential oil from different parts of Alpinia zerumbet (Pers.) Burtt et Smith. Chin J Pharm Anal 2010, 30(8):1399-1403.

13. de Araújoa FYR, de Oliveiraa GV, Gomesa PXL, Soaresa MA, Silvaa MIG, Carvalhob AF, de Moraesa MO, de Moraesa MEA, Vasconcelosa SMM, Vianaa GSB, de Sousaa FCF, Macêdoa DS: Inhibition of ketamine-induced hyperlocomotion in mice by the essential oil of Alpinia zerumbet: possible involvement of an antioxidant effect. J Pharm Pharmacol 2011, 63(8):1103-1110.

14. Zhang YW, Morita I, Nishida M, Murota SI: Involvement of tyrosine kinase in the hypoxia/reoxygenation-induced gap junctional intercellular communication abnormality in cultured human umbilical vein endothelial cells. J Cell Physiol 1999, 180(3):305-313.

15. Ou HC, Lee WJ, Lee IT, Chiu TH, Tsai KL, Lin CY, Sheu WHH: Ginkgo biloba extract attenuates ox-LDL-induced oxidative functional damages in endothelial cells. J Appl Physiol 2009, 106(5):1674-1685.

16. Lee SM, Yoon MY, Park HR: Protective effects of Paeonia lactiflora pall on hydrogen peroxide-induced apoptosis in PC12 cells. Biosci Biotechnol Biochem 2008, 72(5):1272-1277.

17. Alabsi AM, Bakar SAA, Ali R, Omar AR, Bejo MH, Ideris A, Ali AM: Effects of Newcastle disease virus strains AF2240 and V4-UPM on cytolysis and apoptosis of leukemia cell lines. Int J Mol Sci 2011, 12(12):8645-8660.

18. Liu LN, Mei QB, Liu L, Zhang F, Liu ZG, Wang ZP, Wang RT: Protective effects of Rheum tanguticum polysaccharide against hydrogen peroxide-induced intestinal epithelial cell injury. World J Gastroenterol 2005, 11(10):1503-1507.

19. Wang B, Peng $L$, Zhu $L$, Ren P: Protective effect of tota flavonoids from Spirodela polyrrhiza (L.) Schleid on human umbilical vein endothelial cell damage induced by hydrogen peroxide. Colloids Surf B Biointerfaces 2007, 60(1):36-40.

20. Nakamura YK, Dubick MA, Omaye ST: $\gamma$-Glutamylcysteine inhibits oxidative stress in human endothelial cells. Life Sci 2012, 90(3-4):116-121.

21. Yang S, Zhu H, Li Y, Lin H, Gabrielson G, Trush MA, Diehl AM: Mitochondrial adaptations to obesity-related oxidant stress. Arch Biochem Biophys 2000, 378(2):259-268.

22. Diehl AM, Chacon MA, Wagner P: The effect of chronic ethanol feeding on ornithine decarboxylase activity and liver regeneration. Hepatology 1988, 8(2):237-242.

23. Shen XC, Qian ZY: Effects of crocetin on antioxidant enzymatic activities in cardiac hypertrophy induced by norepinephrine in rats. Pharmazie 2006, 61(4):348-352.

24. Park HJ, Zhang Y, Georgescu SP, Johnson KL, Kong D, Galper JB: Human umbilical vein endothelial cells and human dermal microvascular endothelial cells offer new insights into the relationship between lipid metabolism and angiogenesis. Stem Cell Rev 2006, 2(2):93-102.

25. Cappello C, Saugel B, Huth BS, Zwergal HA, Krautkaramer M, Furman C, Rouis M, Wieser B, Schneider HW, Neumeier D, Brand K: Ozonized low density lipoprotein (ozLDL) inhibits NF-KB and IRAK-1-associated signaling. Artherioscler Thromb Vasc Biol 2007, 27(1):226-232.

26. Chowdhury SKR, Sangle GV, Xie XP, Stelmack GL, Halayko AJ, Shen GX: Effects of extensively oxidized low-density lipoprotein on mitochondrial function and reactive oxygen species in pocine aortic endothelial cells. Am J Physiol Endocrinol Metab 2010, 298(1):E89-E98.

27. Sharma A, Bernatchez $P$, de Haan JB: Targeting endothelial dysfunction in vascular complications associated with diabetes. Int J Vasc Med 2012, doi:10.1155/2012/750126.

28. Drǒge $W$ : Free radicals in the physiological control of cell function. Physiol Rev 2002, 82(1):47-95.

29. Gauthman K, Maulik M, Kumari R, Manchanda SC, Dinda AK, Maulik SK: Effect of chronic treatment with bark of Terminalia arjuna: a study on the isolated ischemic-reperfused rat heart. J Ethnopharmacol 2001, 75(2-3):197-201.

30. Bhattacharya SK, Bhattacharya A, Sairam K, Ghosal S: Effect of bioactive tannoid principles of Emblica officinalis on ischemia-reperfusion-induced oxidative stress in rat heart. Phytomedicine 2002, 9(2):171-174.

31. Rajak S, Banerjee SK, Sood S, Dinda AK, Gupta YK, Gupta SK, Maulik SK: Emblica officinalis causes myocardial adaptation and protects against oxidative stress in ischemic-reperfusion injury. Phytother Res 2004, 18(1):54-60.

32. Thallinger C, Urbauer E, Lackner E, Graselli U, Kostner K, Wolzt M, Joukhadar C: The ability of statins to protect low density lipoprotein from oxidation in hypercholesterolemic patients. Int J Clin Pharmacol Ther 2005, 43(12):551-557.

33. Mei $X, X u$ D, Xu S, Zheng Y, Xu S: Novel role of Zn (II)-curcumin in enhancing cell proliferation and adjusting proinflammatory cytokine-mediated oxidative damage of ethanol-induced acute gastric ulcers. Chem Biol Interact 2012, 197(1):31-39.

34. Cacciatore I, Cornacchia CC, Pinnen F, Mollica A, Stefano AD: Prodrug approach for increasing cellular glutathione levels. Molecules 2010, 15(3):1242-1264 
35. Grassi D, Desideri G, Ferri C: Cardiovascular risk and endothelial dysfunction: the preferential route for atherosclerosis. Curr Pharm Biotechnol 2011, 12(9):1343-1353.

36. Koh KK, Oh PC, Quon MJ: Does reversal of oxidative stress and inflammation provide vascular protection? Cardiovasc Res 2009, 81(4):649-659.

37. Tao L, Shen XC, Peng J, Bo S: Experimental study on the anti-inflammatory and analgesic effects in vivo of essential oil from frucus Alpiniae zerumbet in mice. Chin Hosp Pharm J 2010, 30(9):722-724.

doi:10.1186/1472-6882-12-174

Cite this article as: Shen et al:: Evidence-based antioxidant activity of the essential oil from Fructus A. zerumbet on cultured human umbilical vein endothelial cells' injury induced by ox-LDL. BMC Complementary and Alternative Medicine 2012 12:174.

\section{Submit your next manuscript to BioMed Central and take full advantage of:}

- Convenient online submission

- Thorough peer review

- No space constraints or color figure charges

- Immediate publication on acceptance

- Inclusion in PubMed, CAS, Scopus and Google Scholar

- Research which is freely available for redistribution 